\title{
THE STUDY OF THE EFFECTIVENESS OF TRAINING THE PRINCIPLES OF IMPROVING THE RELATIONSHIPS BASED ON GOTTMAN'S METHOD ON COUPLES' MARITAL SATISFACTION IN TEHRAN
}

\author{
Neda Nikounejad \\ M.A Graduated in General Psychology, Islamic Azad University, Science and Research, Ayatollah \\ Amoli Branch, Amol, Iran \\ nedanikoonezhad@yahoo.com \\ Habib Allah Naderi \\ The Faculty Member of Humanities and Social Sciences College, Mazandaran University, Babolsar, \\ Iran
}

\begin{abstract}
Background and Aims: marital satisfaction is one of the most important factors of progress and achieving life goals which is affected by couples' emotional stability. Therefore, the purpose of this research was to study the effectiveness of training the principles of improving the relationships based on Gottman's method on couples' marital satisfaction in Tehran. Materials and Method: It was a quasiexperimental research with pretest-posttest and control group. Statistical population involved all the couples without child that at least two years have passed since their marriage and they referred to psychotherapy and family health clinics in Tehran in 2013 and 2014. The sample included 40 couples who referred to these clinics to get marital counseling and they were selected by random cluster sampling. Then, they randomly divided into control and experimental groups $(20$ couples in each group). ENRICH couple scale (1997) and Gottman's couples' therapy scale (2009) was used to collect data in both pretest and posttest. The experimental group exposed to the independent variable (training the principles of improving the relationships based on Gottman's method) for two sessions of five hours. Statistical analyses performed to analyze data included ANCOVA test.

Findings: The findings showed that training the principles of improving the relationships based on Gottman's method had no significant effect on couples' marital satisfaction $(\mathrm{P}>.05)$; but has been effective on its subscales (emotional relationships, quality of sexual relationships s, trust, compromise and commitment $)(\mathrm{P} \leq .05)$.

Results: The results showed that training the principles of improving the relationships based on Gottman's method can be a very effective way to increase marital satisfaction subscales and improve the couples' relationships.
\end{abstract}

Keywords: improving the relationships, marital satisfaction, Gottman

\section{INTRODUCTION}

Establishing relationships $\mathrm{s}$ with people is very important for man as a social being because human beings innately want to be in public and away from the quiet and solitude since loneliness is associated with mental illness such as anxiety and depression. Establishing intimate relationships, especially after mental and physical maturity is necessary for every adult and these relationships s, especially with the opposite sex are at peak at a young age, so that the person (male and female) is made to select mate, marry and form family. A high percentage of people make marital relationships at a stage of their (Halford, translated by Tabrizi et al., 2014). Husband and wife after marriage, more than anything else, realize that the first step to achieve peace together is their ability to communicate appropriately. However, expectations of many couples from marriage are high and they soon realize that their relationships do not meet these expectations. Thus, turmoil of relationships is a common problem in most Western societies (Halford, translated by Tabrizi et al., 2014) and Iran. 
Relationships are valuable in resolving interpersonal conflicts. Relationships skills by strengthening social protections can be effective in increasing marital satisfaction. Satisfaction is referred to overall perceptions, feelings, beliefs, attitudes, responses, agreements and personal interests in marital life and satisfaction from that (Bakhshi, Asadpour and Khodadadyzadeh, 2007). The results of researches indicate that relationships skills are positively correlated with marital satisfaction and family conflicts resolution process can be simplified by enhancing these skills, (Ebrahimi and Janbozorgi, 2008; Nazari and Navabinezhad, 2005; Aslani, 2004; Ghalili, Ahmadi and Fatehizadeh, 2006, Asoudeh, et al., 2011; McCullough et al., 1998; Robinson \& Blanton, 1993; Nicole, 2006; Santayana, 2007; Amato, 2005).

Relationships are an important variable in understanding martial performance (Rasuli, 2001). Research suggests that marital relationships are a strong predictor of marital quality (Gottman, 1999). Kind of couples' interactions in living environment has direct relationships with feeling miserable or happy. Couples who experience deep, logical, friendly and intimate emotional relationships are successful people with high self-confidence, optimistic, happy and with a sense of happiness. Conversely, couples who do not have appropriate emotional relationships together are solitary, grumpy, with a very low level of consistency in society, unsuccessful, always disappointed with negative and with a sense of misery. Good relationships can improve communications and increase friendship, trust and support between couples. Ineffective relationships may weaken links and create distrust and hatred (Gillpatrick, 2008). If the couple do not right relationships skills and conflict resolution, conflicts continue verbally and then behaviorally and gradual destruction begins in couples adabtability (Douglass, Frazier and Douglass, 1995). Therefore, relationships problems are the most common and devastating problems in failed marriages (Yalcin and Karahan, 2009; Gurman, 2008) since dysfunctional relationships patterns cause important issues of life remain unresolved and be recurring source of conflict between couples ( Halford, translated by Tabrizi et al., 2014).

To improve marital satisfaction, therapeutic and educational approaches can be used. Programs of prevention and improvement of martial relationships refer to any intervention during which destructive relationships behaviors are reduced and good relationships behaviors are improved and as a result dysfunction in interpersonal relationships is prevented (Cuninghham, 2003). Gottman is one of the psychologists of marital area that has developed various educational programs to strengthen married couple's relationships. Gottman training program consists of educational services designed to enhance and enrich the relationships between close family members, especially spouses. This view emphasizes the significance of recognizing beliefs of people about cause of problems and helps clients learn skills that enable them to solve problems (Nazari and Navabinezhad, 2005).

Gutman believes that although capabilities and weaknesses of marriages are intensified under external crises and conditions such as unemployment or financial problems, this crisis alone are not reasons for marriage break-up. An issue such as less or much sexual relations is not the only factor. Even having adaptability and agreement in each case is not the factor for stability of marriage and success because in many happy marriages also experience dissatisfaction. What is important is agreement on what is acceptable (Gottman and Silver, translated by Ghorachedaghi, 2014).

Gottman's theory is an integrated approach and got help from principles and foundations of various therapeutic theories (Gottman, 1991). It support system theory where it says like a cycle, woman is influenced by husband and the husband by woman. It also supports existential view because it does not just look that what these conflicts are related to, but looks beyond those conflicts and in fact dreams of life and when these dreams are described, it supports narrative therapy.

Gottman method also supports a Psychoanalytic perspective since dreams usually refer to childhood of person and symbolic meanings of situations that have been somehow painful, and it supports behavioral approach where seeks behavior change because believes that the best way to change the results instead of trying to change perception of individual is changing behavior as perception comes after behavior. Thus, all these different psychotherapies are supported with findings of Gottman (Randall, 2001). 
According to Gottman (1999) couples should learn how to calm the atmosphere, regain their composure and focus his attention again. They need to figure out how to adjust their intense and different emotions. Calming oneself and others not only paves the way for a fruitful dialogue, but also each spouse has significant contribution in emotional and physical health (Hicks et al., 2004). According to Gottman, four major negative factors (criticism, contempt, defensive behavior and lack of cooperation) disrupt marriage. For dealing with the negative aspects of marriage, he puts great emphasis on love and respect, and to increase the positive aspects, he notes factors such as showing interest, kindness, attention, gratitude, sympathy, empathy, being receptive, wit and having sharing in happiness (Gottman et al., 2002). Educational practice of Gottman contains seven effective principles to strengthen marital relationships s (Kazemi et al., 2011). These seven ethical principles for success in marriage are: 1. couples should have improve their plans of affection; 2. couples should increase their love and appreciation; 3. couples should getting closer to each other instead of keeping away; 4. couples should let their spouse influence them; 5. couples should try that put themselves in place of their spouses, so they could solve resolvable problems; 6 . couples should overcome persistent problems; 7. couples should be able to create a shared belief in life by help of each other (Gottman and Silver, translated by Ghorachedaghi, 2014) .

If the couples adhere to these principles in martial life, their relationships most likely will be longlasting and joyful. Results of studies on the effectiveness of psychological interventions and educations show that these interventions and education are effective on marital satisfaction (Abedi, Mosayebi and Arizi, 2013). In this regard, holding training courses of marriage relationships skills with Gottman method for stabilizing martial relationships improved relationships skills of couples, so that this improvement remained for a long time and hope to improve the relationships also increased (Westerop, 2002). The results of another study performed to prevent marital dissatisfaction and divorce basd on Gottman's theory showed that that couples who participated in this program had more positive emotions, better relationships and better problem solving behaviors (Cornelius and Alessi, 2007). Also, the results of study by Johnson (2000), according to Gottman theory entitled behavioral differences on disconsolate and normal couples showed that couples who tend to focus on positive aspects of spouse and have less focus on negative aspects, have happier life, more satisfaction and more sustainable relationships. Therefore, for a happy marriage, couples need to establish an effective and efficient relationship (Karahan, 2007). The results of the other studies suggest that using couples relationship enrichment education based on Gottman theory marital satisfaction and mental health can be significantly increased (Kazemi et al., 2011; Haddadgar and Zare Bahramabadi et al, 2014; Razi, 2012) and martial stress is reduced and marital happiness increased (Sakizadeh, 2013), also emotional Intelligence, martial interactions and marriage style of couples improved (Shayegh Boroujeni, 2010).

Increased rate of divorce in recent years and discontent of couples with each other and disintegration of warm centers of many families and adverse effects of these discontents and separations on family members (Nosrati, 2011), indicate that couples need help of professionals for improving relationships and communication patterns. Given changes and growing complexity of society and development of social relationships, education of relationship skills for preparing people to deal with people and difficult situations especially shared life seems necessary. No doubt if couples have skills in relationship techniques, they can solve many of life problems and enjoy life and have more adaptability. Thus, because of the importance of the family institution and support of family against disintegration and its preserve as a cornerstone of human society and given the importance of communication patterns in marital satisfaction, and using different approaches to family therapy including relationships skills training as techniques to use right communication patterns, education of relationships improvement principles with Gottman method are used for prevention and treatment of marital disputes and decrease of discontent ;as conflicts, disagreements and dissatisfaction in marriage are inevitable and conflict resolution skills training and providing relationships skills and sources that help couples solve marital problems, will be clearly helpful and necessary (Razi, 2012). The difference of Gottman method with other methods is that instead of considering what factors lead to collapse of marriage, cares about what factors make a successful marriage (Kazemi et al., 2011). Given that this training method has got little attention of researchers, improvement of 
relationship between couples through Gottman is one of important issues that should be examined; because counselors and psychologists of counseling centers, family clinics can be used as an effective way to improve a couple's relationship. Therefore, this study aimed to evaluate the effectiveness of principles of improving the relationship based on Gottman method on marital satisfaction of couples in Tehran. To this end, the research hypotheses are:

1- Training the principles of improving the relationship based on Gottman method is effective on marital satisfaction.

2- Training the principles of improving the relationship based on Gottman method is effective on the components of marital satisfaction of couples.

\section{MATERIALS AND METHODS}

The research method has been quasi-experimental with pretest-posttest design and control group and it is an applied research. The study population consisted of all the couples who had referred to psychotherapy clinics in Tehran in the years 2013 and 2014 to get marital counseling. The research sample included 40 couples from those referred. Inclusion criterion was couples who had been married at least two years ago, had no children and lived in urban areas of Tehran. Sampling method was random cluster that is Tehran city was divided into four sections (North, South, West and East) was divided. Then, one part (East of Tehran) was randomly selected among four parts and next among East districts of Tehran, a district (district 8) was selected randomly. Then among all psychotherapy and family health clinics in that district, a clinic was randomly selected and among the couples referred to that clinic 40 couples were randomly selected and then randomly assigned to two experimental and control groups (each group of 20 couples). Method of the study was such that ENRICH Marital Satisfaction Scale questionnaire (1997) and Gottman scales of marital therapy (2009) were provided to the couples. In order to respect moral considerations of research, in a briefing session before distributing the questionnaires, a short description of questionnaires was provided to the couples and they were assured that this is purely a research and responses will remain confidential. Then, the intervention of relationship improvement principles training program based on Gottman method was performed for the experimental group, while the control group did not receive this intervention.

The experimental intervention was conducted over two sessions for the experimental group. In a way that every week a session was held for 5 hours and at the end of each session, after summing up the contents, a task was given to the next session. This educational intervention was conducted in a private clinic located in East Tehran and by the researcher in the first and second week of July 2014 carried out for the experimental group. At the end of the intervention program both experimental and control groups completed questionnaires again. Strategies used in each training session were derived from content of relationship improvement principles protocol based on Gottmann (2009). Description of the training protocol sessions are as following:

First session: examining ways of improving love relationship between the couples through increased understanding of self and spouse in the personality, emotional, cognitive, intellectual, interests and tastes areas; understanding his/her concerns and further increase of cognitive space of each of the spouses about each other; training effective ways to increase love, respect and positive interaction between couples, reviving positive emotions, increasing gratitude, enhancing the ability to understand the advantages and disadvantages of spouse; focusing on getting closer to each other and increasing the scale of intimacy, ways of effective listening and speaking skills and effective relationships skills and investigating the factors contributing coldness of relationship and resolving them.

Second Session: training ways to solve resolvable problems, identifying arguments start styles, training the use of compensatory measures, attention to one self's physiology during disputes and training various methods of relaxation; training strategies to improve sexual relationships, training calming each other and the way of agreeing on unresolvable problems, training the importance of accepting influence from husbands and making spouses participate in decision-making, enabling partners to create a common concept in their martial life through creation of inner life by both couples.

In this study, two questionnaires were used to collect data: 
1 .Enrich Marital Satisfaction Scale (47 points form): This scale has 47 items and 12 subscales, of which two subscales emotional Relationship (6 items) and quality of sexual relationships (5 items) in this study were chosen. During the implementation of this scale, the couples were asked to read the items and provide their view in a 5-point Likert scale from strongly disagree to strongly agree mark. For each item a score of one to five was assigned. Of course, scoring some items was reverse. A higher score indicated high marital satisfaction (Olsen and Olsen, 1997). This scale is normalized in Iran and significant solidarity between these scale and family satisfaction questionnaires and life satisfaction has revealed the validity of this test (Ameri et al., 2002). Reliability of that has also been reported as 0.95 by Cronbach's alpha for the overall scale (Soleimanian, 1994).

2-Martial therapy scale Gottman (2009): This scale has 68 items and 3 subscales (trust, compromise and commitment) that the dimension of trust (with 21 items) and commitment (with 20 items) have been set as a 5-point Likert scale from strongly disagree to completely agree and compromise dimension (with 27 items) as right- wrong answer. In case of trust dimension, the more is persons' agreement with the items, the less is trust rate and vice versa. But in case of compromise and commitment dimension, the more persons' agreement with items, the higher is compromise and and commitment to the spouse and vice versa. This questionnaire has been standardization in Iran.

In this study, in order to ensure the validity of questionnaires the views of experts and professors of Psychology department in Islamic Azad University, Science and Research Ayatollah Amoli have been used. Thus, face and content validity of scales have been confirmed by psychology professionals. Also, the reliability of the questionnaires by Cronbach's alpha for scales of Enrich Marital Satisfaction and martial therapy of Gottman was found as 0.89 and 0.93 respectively that is acceptable. Statistical analysis of data was conducted using statistical software SPSS17 and descriptive statistics (mean and standard deviation) and inferential statistics (Covariance analysis / ANCOVA).

\section{FINDINGS}

In Table (1) descriptive data related to overall marital satisfaction and its subscales in both pre and post tests are presented. Results in Table 1 show that the average score of overall marital satisfaction and mean of scores on the subscales (emotional connection, quality of sexual relationships, trust, compromise and commitment), in the experimental group were higher in posttest than pre-test stage.

In order to determine the effectiveness of the principle of improving the relationships principles based on Gottman method on marital satisfaction and its subscales, analysis of covariance test was used, whose results are brought in Table 2 . According to the results presented in this table there is no significant differences between marital satisfaction in the experimental and control groups in posttest stage $(\mathrm{P}>0.05)$, but there is significant differences in the subscales (emotional connection, the quality of sexual relationships, trust, compromise and commitment) in test and control groups in posttest stage $(\mathrm{P} \leq 0.05)$.This means that training relationship improvement principles based on Gottman method has been able to increase subscales of marital satisfaction (emotional connection, quality of sexual relationships, trust, compromise and commitment) in couples after posttest stage but has not been effective overall martial satisfaction (Table 2 ).

Table 1- Comparison of mean and standard deviation in experimental and control groups in overall score of martial satisfaction and its subscales in pretest and posttest stages

\begin{tabular}{|c|c|c|c|c|c|}
\hline $\begin{array}{c}\text { Statistical } \\
\text { indicators }\end{array}$ & Mean & $\begin{array}{c}\text { Pretest } \\
\text { Standard } \\
\text { Componiation }\end{array}$ & Mean & $\begin{array}{c}\text { Standard } \\
\text { deviation }\end{array}$ \\
\hline $\begin{array}{c}\text { Martial } \\
\text { satisfaction } \\
\text { (overall) }\end{array}$ & $\begin{array}{c}\text { Experiment } \\
\text { Control }\end{array}$ & 137.075 & 19.750 & 169.625 & 14.077 \\
\hline Emotional & Experiment & 133.750 & 10.443 & 134.575 & 8.313 \\
connection & Control & 16.225 & 3.314 & 20.575 & 2.437 \\
\hline Quality of & Experiment & 16.75 & 3.605 & 16.475 & 3.029 \\
sexual & Control & 14.950 & 2.846 & 18.375 & 2.305 \\
\hline
\end{tabular}




\begin{tabular}{|c|c|c|c|c|c|}
\hline relations & & & & & \\
\hline \multirow{2}{*}{ Trust } & Experiment & 42.900 & 27.388 & 71.350 & 27.700 \\
& Control & 47.075 & 22.858 & 47.425 & 21.854 \\
\hline Compromise & Experiment & 59.625 & 19.392 & 86.250 & 14.577 \\
& Control & 51.925 & 22.619 & 51.500 & 22.224 \\
\hline \multirow{2}{*}{ Commitment } & Experiment & 56.425 & 28.541 & 84.050 & 25.497 \\
& Control & 61.375 & 20.250 & 60.500 & 19.348 \\
\hline
\end{tabular}

Table 2- Analysis of covariance of marital satisfaction scores (overall) and its subscales in the study groups in posttest stage

\begin{tabular}{|c|c|c|c|c|c|c|c|}
\hline Source & Components & $\begin{array}{l}\text { Sum of } \\
\text { squares }\end{array}$ & $\begin{array}{l}\text { Degr } \\
\text { ees } \\
\text { of } \\
\text { freed } \\
\text { om }\end{array}$ & $\begin{array}{l}\text { Mean } \\
\text { square }\end{array}$ & $\mathrm{F}$ & $\begin{array}{c}\text { The } \\
\text { significanc } \\
\text { e level }\end{array}$ & $\begin{array}{l}\text { ETA } \\
\text { value }\end{array}$ \\
\hline \multirow[t]{6}{*}{ Pretest } & $\begin{array}{c}\text { Martial } \\
\text { satisfaction } \\
\text { (overall) }\end{array}$ & 3506.667 & 1 & 3506 & $\begin{array}{c}43.14 \\
8\end{array}$ & 0.000 & 0.362 \\
\hline & $\begin{array}{l}\text { Emotional } \\
\text { connection }\end{array}$ & 161.016 & 1 & 161.016 & $\begin{array}{c}33.89 \\
3\end{array}$ & 0.000 & 0.308 \\
\hline & $\begin{array}{l}\text { Quality of } \\
\text { sexual } \\
\text { relations }\end{array}$ & 229.365 & 1 & 229.365 & $\begin{array}{c}64.89 \\
5\end{array}$ & 0.000 & 0.461 \\
\hline & Trust & 15206.241 & 1 & 15206.241 & $\begin{array}{c}37.82 \\
1 \\
\end{array}$ & 0.000 & 0.332 \\
\hline & Compromise & 12287.975 & 1 & 12287.975 & $\begin{array}{c}118.1 \\
84 \\
\end{array}$ & 0.000 & 0.609 \\
\hline & Commitment & 22049.417 & 1 & 22049.417 & $\begin{array}{c}93.73 \\
5 \\
\end{array}$ & 0.000 & 0.552 \\
\hline \multirow{6}{*}{$\begin{array}{c}\text { Group } \\
\text { membership }\end{array}$} & $\begin{array}{c}\text { Marital } \\
\text { Satisfaction } \\
\text { (overall) }\end{array}$ & 117.218 & 1 & 117.218 & 1.442 & 0.000 & 0.019 \\
\hline & $\begin{array}{l}\text { Emotional } \\
\text { connection }\end{array}$ & 50.855 & 1 & 50.855 & $\begin{array}{c}10.70 \\
5\end{array}$ & 0.000 & 0.123 \\
\hline & $\begin{array}{l}\text { Quality of } \\
\text { sexual } \\
\text { relations }\end{array}$ & 36.913 & 1 & 36.913 & $\begin{array}{c}10.44 \\
4\end{array}$ & 0.000 & 0.121 \\
\hline & Trust & 5479.749 & 1 & 5479.749 & $\begin{array}{c}13.6 \\
29\end{array}$ & 0.000 & 0.152 \\
\hline & Compromise & 4605.556 & 1 & 4605.556 & $\begin{array}{c}44.29 \\
6\end{array}$ & 0.000 & 0.368 \\
\hline & Commitment & 195.079 & 1 & 195.079 & 8.290 & 0.000 & 0.098 \\
\hline
\end{tabular}

\section{Discussion and Conclusion}


The results of the present study that investigated the effectiveness of training relationship improvement principles based on Gottman method on martial satisfaction of couples, showed that training relationship improvement principles based on Gottman has not been effective in marital satisfaction but affects its components (emotional connection, quality of sexual relationships, trust, compromise and commitment); so that emotional connection, quality of sexual relationships s, trust, compromise and commitment of couples in the test group have increased after relationship improvement principles based on Gottman method that in line with these result, some studies can be noted in which training relationships skills of marriage based on Gottman method is considered effective in improving communication skills and martial interaction (Kazemi et al., 2011; Haddadgar and Zare Bahramabady, 2014; Razi, 2012; Sakizadeh, 2013; Shayegh Boroujeni, 2010; Johnson, 2000; Vestrop , 2002; Cornelius and Elsie, 2007), because the marital relationships is an essential component in understanding martial performance (Rsuli, 2001) and can be a strong predictor of marital quality (Gottman, 1999) and if the spouses fail to acquire relationships skills properly, verbal and behavioral conflicts appear and persistence of marital conflicts causes dissociation marriage.

It is obvious that healthy relationships s based on compatibility and understanding among family members, especially between husband and wife is the survival factor of durability and growth of life. In contrast, ineffective relationships $\mathrm{s}$ weaken marriage bond and cause incidence of distrust and hatred. Therefore, as the results of various studies show, by training relationships skills, the process of solving marital conflicts can be facilitated (Ebrahimi and Janbozorgi, 2008; Nazari and Navabinezhad, 2005; Amato, 2005) and the couple's emotional relationships s and commitment to each other can be increased (Aslani, 2004; McCloy et al., 1998; Santayana, 2007) and by increasing the mutual understanding of each other and creating love, commitment and integrity in each of the spouses towards the other, feeling of hope and happiness in martial life can be restored to them (Robinson and Blanton, 1993; Nickol, 2006).

Training the principles of relationship improvement based on Gutman method helps couples who concerned with the turmoil in their marital relationship by combining principles and foundations of different treatment theories. This training program is designed to enhance and enrich family relations, especially relations between spouses to help couples identify the cause of problems and strengthen their marital relationship by learning the skills that help them solve their problems, (Nazari and Navabinezhad, 2005). In this program, instead of focus on the factors that cause the collapse of marriage (such as criticism, contempt, defensive behavior and lack of cooperation), factors are emphasize that cause success of marriage (Kazemi et al., 2011). In other words, in this program techniques are taught to couples through which they can recognize their sometimes different emotions, love each other, respect each other, and share their feelings easily, participate in decision-making, understand their spouse's weak and strong points, improve their sexual relations, calm each other in conflicts and by understanding each other's concerns and using effective techniques of listening and engaging in dialogue, identify the causative agents of coldness in marital relation and solve them together . Marital come to know and act together to solve them.

Among possible reasons for effectiveness of training improvement relationship principles based on Gottman method on components of emotional connection, quality of sexual relationships, trust, compromise and commitment, it can be said that with training relationship improvement principles in the experimental group, couples learn right ways of replacing behaviors and new efficient thoughts instead of previous negative ineffective thoughts and behaviors about their spouses and learn to identify factors affecting success of their common life and strengthen them. Also, during training sessions, these couples learn effective communication skills, and this can lead to a positive attitude to themselves and their spouse, better relationship with their partner, creating love and intimacy in life and creation of shared concept in martial life. Also, among possible reasons for the lack of effectiveness of training relationship improvement based on Gottman method on marital satisfaction(overall), it can be said that marital satisfaction other than including elements such as emotional connection, quality of sexual relationships, trust, compromise and commitment, could also include other aspects like spending leisure time, religious beliefs, personality issues, financial issues, parenting, relationship with original family and friends, spouse roles and conflict resolution. In other 
words, marital satisfaction is a construct that cover different factors and all of them should be supplied for achieving optimum satisfaction. Since many of these effective factors in marital satisfaction had not been considered in this study and in training sessions components involved in marital relations have been emphasized more, and just some strategies have been taught to couples for improving them, so although training relationship improvement principles based on Gottman method increased martial satisfaction (overall), but this increase has not been significant.

In sessions of training relationship improvement principles based on Gottman method, this vision was given to the couples that they have negative and false thoughts about the state of their marriage that cause a negative bias towards their wife. So, they were instructed to focus on the factors on positive factors affecting the success of martial life rather than on destructive factors. This program, by increasing exchange of positive behavior, boosting companionship and sensational and emotional fusion, behavior control and function of couples will improve the quality of couples' relationships $\mathrm{s}$ and intimacy and affection between them. As a result, when couples feel that experience deep emotional, logical, friendly and intimate relationships, they continue their shared life with optimism and happiness. In general, the results of this study showed that training relationship improvement principles based on Gottman Method has been effective in increasing relationships skills of couples (emotional connection, quality of sexual relations, trust, compromise and commitment).

Helping couples who are experiencing marital turmoil, using relationship improvement principles based on Gottman method in family counseling centers can be an effective step in enhancing communication skills of couples and reduce couples' marital conflicts and its consequences such as divorce. The results of this research encourages professionals to attach more importance to the psychological aspects of martial life; resulting in better and faster improvement of marital relations. On limitation of this study is that this is performed on couples who referred to one of the family counseling centers in Tehran with last at least two years of marriage and had no children and the results may not be generalizable to all couples referring to counseling centers in other cities of the country or couples who have children. Therefore, this study suggests that future studies by taking more samples and conducting a longitudinal study in society and other statistical sample can confirm the results of this study.

\section{REFERENCES}

1- Asoudeh, MH; Daneshpoor, M; Khalili, Sh; Gholamali Lavasani, M; Abu Ali Shabani, M; Dadras, A. (2011). Iran's successful family functioning: communication. Social and Behavioral Sciences, 30: 371-367.

2- Ebrahimi, A.; Janbozorgi, M. (2008). The relationship between communication skills and marital satisfaction. Psychology in dealing with religion, first year, No. 2: 164-147.

3- Aslani, Kh. (2004). The role of family communication skills on the performance of married students. Address access www.uswr.ac.ir

4- Bakhshi, H, Asadpoor, M, Khodadadizadeh, A. (2007). Depression and marital satisfaction among couples in Rafsanjan. The Journal of Qazvin University of Medical Sciences, Vol. XI, No. 2 (successive 43), 7 pages.

5- Haddadgar, S, Zare Bahram Abadi, M. (2014). Gottman method based on the couple's communication effectiveness enrichment program on marital satisfaction of wives are left with drug addicts. First National Congress of Education and Psychology, Shiraz, opinion makers, Andishe Sazan Mobtaker Javan Company URL: www.civilica.com [Visit date: 1 June 2016.

6- Razi, S. (2012). The effectiveness of dispute resolution skills training to Gottmann way to increase marital satisfaction in married women referred to the health center 5 Tehran municipality. Family Counseling master's thesis, Faculty of Psychology and Educational Sciences, Allameh Tabatabai University in Tehran.

7- Rasouli, M. (2001). The relationship between communication patterns and communication patterns of their parents, wives and husbands student at Tehran University. Master's thesis, University of Teacher Education. 
8- Sakizadeh, Fatima. (2013). Study Skills Training marriage Gottman model of marital stress and women's marital happiness. Master thesis, Faculty of Psychology and Educational Sciences, Tarbiat Moallem University of Tehran.

9- Soleimanian, AA. (1994). The effect of irrational thinking, cognitive approach based on marital satisfaction Teacher Training University. Advice and guidance master's thesis, Faculty of Psychology and Educational Sciences, Tarbiat Moallem University of Tehran.

10- Shayegh Boroujeni, L. (2010). The effect of psychological intervention on emotional intelligence skills marriage Gottman model, the stability of marital interaction style among couples in marriage. Counseling master's thesis, University of Isfahan.

11- Abedi, A.; Mosayebi, E., Arizi, HR. (2013). A meta-analysis on the effectiveness of psychological interventions for sexual satisfaction (Iran 2004-10). Journal of Counseling and Family Therapy, Volume 3, Number 2: 259-232.

12- Ameri, F; Noorbala, AA, Ejei, J., Rasoulzadeh Tabatabaei, SK. (2002). The effect of marital discord strategic family therapy interventions. Journal of Psychology, Volume 7, Number 3, row 27: 232-218.

13- Ghalili, Z, Ahmadi, SA; Fatehizadeh, M. (2006). Couple Therapy: Interview with couples in conflict. New psychotherapy, 39 and 40: 78-59.

14- Kazemi, P; Aghamohamadian Sherbaf, HR, Modarres Gharavi, M; Mahram, B. (2011). Effectiveness of improving the quality of life of couples on marital satisfaction and mental health. Research in clinical psychology and counseling, first year, (2): 86-71.

15- Gottman, John; Silver, Non. (2014). Seven ethic to succeed in marriage. Fourth edition, translated by Mehdi Ghorachedaghi, Tehran: Asim.

16- Nosrati, A. (2011). Family and marital satisfaction survey of working women and housewives in the city of Tabriz. Thesis, Faculty of Psychology of Payam Noor university of Marand Branch.

17- Nazari, AM; Navabinezhad, Sh. (2005). Evaluate the effect of improving the relationship between the marital satisfaction of both working. New research and consulting, fourth year, numbers 13: 59-35.

18- Halford, Kim. (2014). Even short-term therapy, "helping couples to help themselves." Third edition, translated by Mostafa Tabrizi, Mozhdeh Kardani, Forough Jafari and Asadullah Moazami Goudarzi, Tehran: Fararavan.

19- Amato, P. R. (2005). The impact of family formation change on the cognitive, social, and emotional well-being of the next generation. The Future of Children (overcoming barriers to stable marriage), 15(2): 75-96.

20- Cornelius, T. L.; Alessi, G. (2007). The Effectiveness of Communication Skills Training with Married Couples: Does the Issue Discussed Matter?. The Family Journal: Counseling and Therapy for Couples and Families, 2 (15): 124-132.

21- Cuninghham, O. Mary. (2003). A Secondary Prevention and Enhancement Program for Married Couples. Texas A \& M University.

22- Douglass, I. V.; Frazier, M. and Douglass, R. (1995). The MaritalProblems Questionnaire (MPQ), A short screening instrument formarital therapy. Journal of Family Issues, 17: 386407.

23- Gillpatrick, S. (2008). Seven Ways couples add conflict to conflict. Centerstone, Wellness programWard C, Bochner S, Farnham A. The psychology of culture shock, 2nd ed. London: Routledge.

24- Gottman, J. M. (1991). Predicting the longitudinal course of marriages. Journal of Marital and family Therapy, 17 (1): 3-7.

25- Gottman, J. M. (1999). The Marriage Clinic: A scientifically based marital therapy. New York.

26- Gottman, J.; Murray, J.; Swanson, C. T.; Rebeca Swanson, K. (2002). The mathematics of marriage, Dynamic Nonlinear Models. Massachusetts Institute of Technology, MIT Press.

27- Gottman, J.M.; and Gottman, J. S. (2009). Gottman couples therapy scale. The Gottman Institute.

28- Gurman, A.S. (2008). Clinical handbook of couple therapy. New York: The Guilford Press. 
29- Hicks, M.W., McWey, L.M., Benson, K.E. \& West, S.H. (2004). Using what premarital couples already know to inform marriage education: Integration of a Gottman model perspective. Contemporary Family Therapy, 26, 1, 97-113.

30- Johnson, S. A. (2000). John Gottmann's research on the Behavioral Differences between Distressed and non Distressed Couples. Salisbury State University.

31- Karahan, T.F. (2007). The effects of a couple communication program on conflict tendency among married passive couples. Educational Sciences: Theory \& Practice, 7 (2), 845-858.

32- McCullough, M. E.; Rachal, K. C.; Sandage, S. J.; Worthington, Jr. E. L.; Brown, S. W.; Hight, T. L. (1998). Interpersonal forgiving in close relationships: II. Theoretical elaboration and measurement. Journal of Personality and Social Psychology, 75, 6: 1586-1603.

33- Nicole, M. (2006). Personality predictors of relationship satisfaction among engaged and marriage couples: A analysis of actor and partner effects access this item. All Theses and Dissertations, Paper 552, Brigham Young University, BYU ScholarsArchive.

34- Olson, D.H.; Olson, A. (1997). Enrich Canada, inc. Journal of Family Ministry, 11: 28-53.

35- Randall, C. Wyatt. (2001). An Interview with John Gottman. Available on: https://www.psychotherapy.net/interview/john-gottman

36- Robinson. L.; and Blanton, C. (1993). Marital strengths in enduring marriages. Family Relations, 42, 1, Academic Research Library: 38.

37- Santayana, G. (2007). Spouse's personality may be hazardous to your health. Weds Worth.

38- Westerop, K. (2002). Building healthy couple relationship: Do communication skills, gender, hope, and family types make a difference?.Trinity western university, Canada.

39- Yalcin, M.B., and Karahan, F. (2009). The effect of couple communication program on passive conflicttendency among married couples. Department of Educational Sciences, 55139 Kuruplit/ Samsun, Turkey, 845- 858. 